\title{
Medical migration within Europe: opportunities and challenges
}

\author{
Authors: Kate Ling ${ }^{A}$ and Paul Belcher ${ }^{B}$
}

\begin{abstract}
The free movement of European citizens to live and work within the European Union (EU) is one of the fundamental pillars of the European single market. Recent EU legislation on the recognition of professional qualifications (to take effect January 2016) updates the framework within which doctors and others can migrate freely between EU member states to practise their profession. UK organisations lobbied extensively to change aspects of the original proposals, in particular those that threatened to 'water down' public protection in the interest of free movement. The legislation finally adopted significantly increases safeguards for patients and the public. The revised law covers the rules to be applied by regulators on (for example) assuring language competence, warning 'blacklists' of practitioners subject to sanctions, 'fast track' registration based on mutual recognition of professional qualifications, agreed minimum education and training requirements for mutual recognition, and encouragement of continuing professional development. Drafting of detailed secondary legislation is ongoing and poses opportunities and challenges for patient safety, quality of care and transparency.
\end{abstract}

KEYWORDS: Europe, professional migration, professional qualifications, continuing professional development, language controls, professional regulation

\section{Introduction}

The European Union (EU) has recently passed new legislation on the recognition of professional qualifications, Directive 2013/55/EU ${ }^{1}$ (an update of existing Directive 2005/36/EU ${ }^{2}$ ), which poses new opportunities and challenges for doctors wanting to live and work in a European country other than the one in which they originally qualified. The NHS has long relied on medical migration from abroad, increasingly from the rest of the EU as well as from the English-speaking Commonwealth countries: over $10 \%$ of doctors on the General Medical Council (GMC) register hold a primary qualification from another EU member state. Inward migration benefits the host

Authors: Asenior European policy manager, NHS European Office, Brussels, Belgium; ${ }^{B}$ principal EU adviser, Royal College of Physicians, London, UK country, but it can also present challenges when the incoming doctor - even though he or she holds a medical qualification recognised as equivalent to a British qualification - has been trained in a language other than English and is used to working in a healthcare system with culture and expectations that differ from UK 'norms'. Recent high-profile cases such as that of Dr Daniel Ubani, a German doctor who inadvertently caused the death of a patient, have highlighted concerns about the competence of a minority of incoming doctors.

The free movement of European citizens to live and work within the EU is one of the fundamental pillars of the European single market, and the Directives lay down the framework within which doctors and others can migrate freely between EU member states and practise their profession without having to jump through onerous hurdles. Healthcare professionals (doctors, dentists, nurses responsible for general care, midwives and pharmacists) who hold certain qualifications listed in the Directive's annexes as meeting minimum requirements and are currently registered with a regulatory body in one EU member state, can register to practice in any other member state without having to satisfy further tests or formalities under the Directive's 'automatic recognition' procedures. Professional registration (fitness to practice) does not remove the need for employers to ensure that the applicant has the necessary skills and competences to perform the role for which he or she is applying (fitness for purpose).

The European Commission originally consulted in 2011 on proposals to revise the legislation, which were debated extensively in the European Parliament and Council throughout 2012-13. Numerous stakeholder groups, including representatives of the (medical and other) professions such as the Royal College of Physicians, ${ }^{3}$ regulatory bodies, educational bodies, and employee and employer organisations (such as the NHS European Office ${ }^{4}$ ) lobbied extensively to challenge and change aspects of the proposals, in particular those that threatened to 'water down' public protection in the interest of free movement. The legislation finally adopted significantly increased safeguards for patients and the public. The following aspects are particularly relevant to the medical profession.

\section{Language controls}

Regulators will be allowed to check language skills before granting access to the profession, but after recognising the 
validity of the qualification. It is up to member states how to implement this in accordance with their national systems: in the UK the GMC has made the granting of a licence to practice conditional to European applicants, upon providing evidence that they have the necessary knowledge of English to communicate effectively. In addition, language competence will be taken into account by responsible officers for the purposes of revalidation, and a new category has been created of impairment to fitness to practice owing to lack of linguistic skills. As now, employers will also be able to undertake language checks when recruiting for a particular job (fitness for purpose). This does not, however, mean that all doctors coming to the UK from the EU can be made to sit a standard test in the same way as overseas (non-EU) applicants to the GMC register: regulators can ask for satisfactory evidence of linguistic proficiency but cannot insist on the precise form that this evidence takes. If the doctor is unable to supply appropriate evidence he or she can be asked to sit a test before being granted a licence to practice.

\section{Warning system}

Current evidence is that there is wide variation across EU member states in the way medical regulatory bodies manage professional issues involving quality and patient safety. ${ }^{5}$ Under the new legislation, member states will have to establish an 'alert system' to warn each other within 3 days when a health professional is banned or his or her practice restricted, even temporarily. This is a significant improvement on the current situation whereby 'rogue' professionals can continue to practice by slipping across national borders, but the devil will be in the detail of this legislation. For example, how will the system work for professionals with dual registration (eg as a doctor and a pharmacist), and - given the inconsistencies between countries in the way in which similar situations are currently handled - what information exactly will regulators be obliged to communicate and at what stage?

\section{European professional card}

This will not be a 'card' as such, but a 'fast-track' form of electronic documentation attesting to a professional's qualifications and registration status, exchanged between regulatory bodies and intended to replace the need for further paper checks. The European Commission (EC) has consulted on whether and how to introduce the card for a small number of vanguard professions, including medical practitioners, and will issue definite proposals shortly. The intention is to simplify and speed up procedures, which would clearly be an advantage for both outgoing and incoming doctors, but has raised patient safety concerns among regulators and others because of the potential for abuse.

\section{Minimum training requirements}

Health professionals only get automatic recognition if they meet all the minimum training requirements for their profession, as set out in the Directive. The new rules changed the minimum training requirements for doctors to 5 years and 5,500 hours of training instead of 6 years or 5,500 hours.
This was an important victory for the UK because it ensured the continuance of shorter postgraduate medical and dental degrees ( 4 years plus one foundation year $=5$ years). However, the requirements will be subject to updating and the UK will need to be vigilant to ensure that innovative delivery of future training, perhaps in a more modular or discontinuous pattern than at present, does not fall foul of EU rules.

\section{Continuing professional development}

Member states will also be expected to encourage continuing professional development (CPD) for doctors, dentists, nurses, midwives and pharmacists, and to report to the EC periodically on the progress made. At the same time, the EC has commissioned a study led by a consortium of organisations including CPME (the Standing Committee of European Medical Doctors) to compare and contrast existing CPD systems, which vary widely across the EU/European Economic Area/European Free Trade Association countries. In some countries there is a mandatory process clearly linked to revalidation; in others CPD is voluntary; and overall there is wide variability in the duration and content of CPD required in order to stay on the medical register, with a lack of effective validation, sanctions or enforcement in a small minority of countries. This study is due to finish by the end of 2014 and will no doubt result in recommendations for further work.

\section{Common training frameworks and introduction of new medical and dental specialties}

The new Directive contains provisions for medical and dental specialties that are not currently recognised as equivalent across national borders to be recognised on the basis of mutually agreed length and content of training, if enough countries agree. This can be done in future only by secondary (delegated) legislation prepared by the EC in consultation with relevant stakeholders such as professional bodies.

\section{Discussion - what next?}

The new Directive must be transposed into domestic law within 2 years after entering into force (ie 18 January 2016). Many of the detailed rules remain to be fleshed out: the EC will need to do this by developing further implementing and delegated legislation during 2014 and 2015, eg on the documentation and procedures for obtaining the professional card or for operating the warning system, and the Government (Department of Business, Innovation and Skills) and the Health Departments are heavily engaged in this process. It will also be important to keep abreast of future developments such as proposals to update the lists of recognised medical qualifications and the 'knowledge and skills' content of basic medical training, the length of specialist medical and dental training, and recognition of new medical and dental specialties - this can be done in future by the EC using delegated powers, with 'appropriate and transparent' consultation, with 'experts' such as regulators, professional bodies, educational institutions and (where relevant) 'social partners' (associations of employers/ trade unions). UK stakeholders such as regulatory and 
professional bodies and NHS employers will wish to influence this process, directly as 'experts' or indirectly, eg by briefing members of the European Parliament, to secure the best possible outcomes for the safety, quality and transparency of NHS services.

\section{References}

1 Directive 2005/55/EC of the European Parliament and of the Council of 20 November 2013 amending Directive 2005/36/EC on the recognition of professional qualifications and Regulation (EU) No 1024/2012 on administrative co-operation through the Internal Market information System ('the IMI Regulation'). Available online at http://eur-lex. europa.eu/legal-content/EN/TXT/PDF/?uri=CELEX:32013L0055\& rid $=1$ [Accessed 2 September 2014].

2 Directive 2005/36/EC on the recognition of professional qualifications of the European Parliament and of the Council of 7 September 2005 (Text with EEA relevance) (OJ L 255, 30.9.2005, p. 22). Available online at http://eur-lex.europa.eu/legal-content/EN/TXT/PDF/?uri= CELEX:02005L0036-20140117\&rid=1 [Accessed 2 September 2014].
3 Royal College of Physicians. Consultation on the EU professional qualifications directive: Response. London: RCP, 2011. Available online at www. rcplondon.ac.uk/sites/default/files/rcp-response-to-consultationon-eu-professional-qualifications-directive-15-march-2011.pdf [Accessed 2 September 2014].

4 NHS European Office. New EU law on mobility of health professionals across Europe: what this means for the NHS. Briefing, October 2015, Issue 15. Available online at http://www.nhsconfed. org/ /media/Confederation/Files/Publications/Documents/ EU-law-mobility-health-professionals.pdf?dl=1 [Accessed 6 November 2014].

5 Risso-Gill I, Legido-Quigley H, Panteli D, Mckee M. Assessing the role of regulatory bodies in managing health professional issues and errors in Europe. Int J Qual Health Care 2014;26(suppl 1):1-10

Address for correspondence: Ms Kate Ling, NHS European Office, rue Marie-Thérèse 21, 1000 Brussels, Belgium. Email: kate.ling@nhsconfed.org

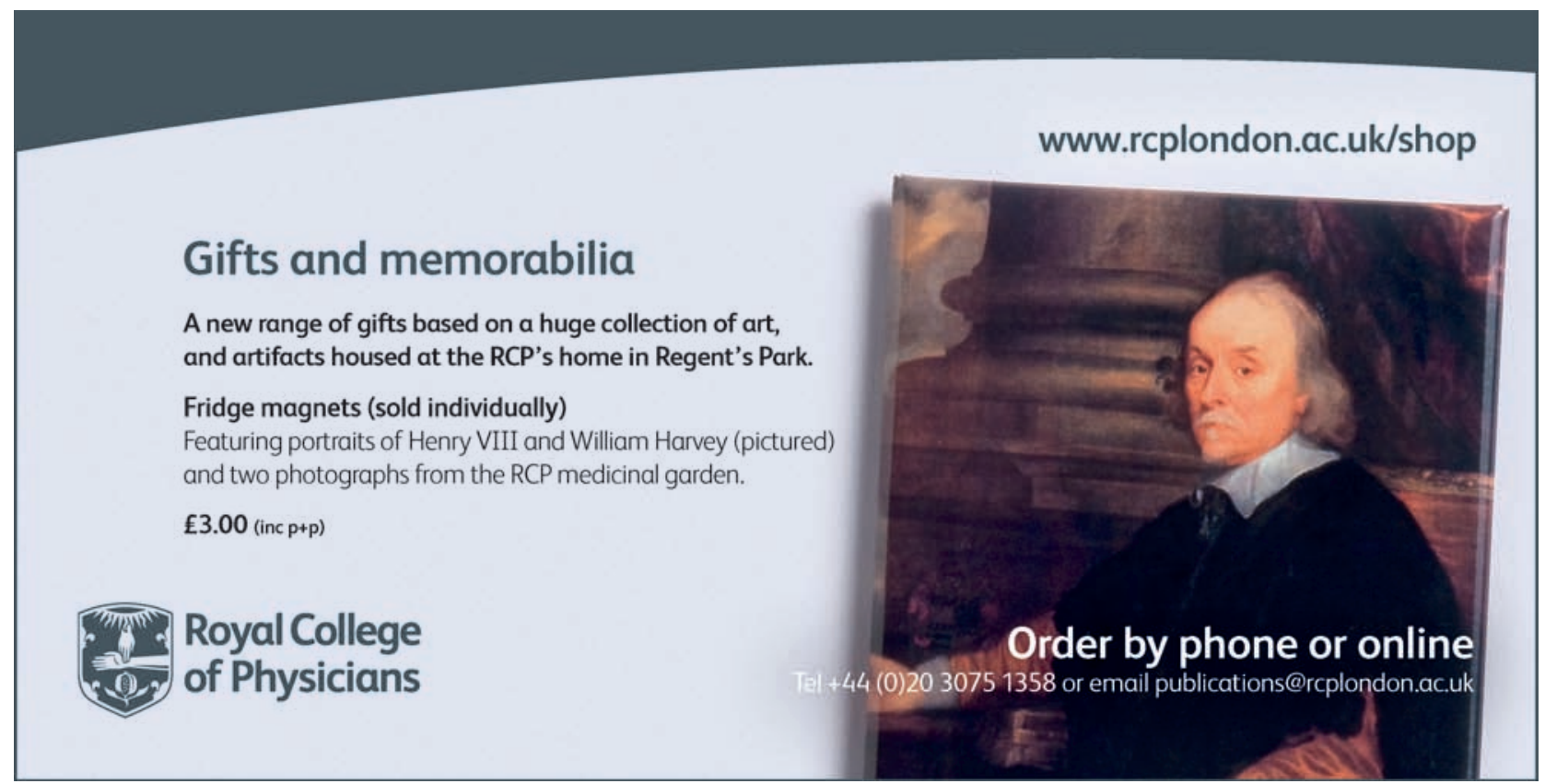

